\title{
Processing of whey modulates proliferative and immune functions in intestinal epithelial cells
}

\author{
Duc Ninh Nguyen, ${ }^{\dagger} \dagger$ Per T. Sangild, ${ }^{*}$ Yanqi Li, ${ }^{*} \ddagger$ Stine B. Bering, ${ }^{*}$ and Dereck E. W. Chatterton ${ }^{*}{ }^{1}$ \\ ${ }^{*}$ Comparative Pediatrics and Nutrition, Department of Veterinary Clinical and Animal Sciences, and \\ †Department of Food Science, University of Copenhagen, Frederiksberg C 1870, Denmark \\ $\ddagger$ Arla Foods Ingredients Group P/S, Viby 8260, Denmark
}

\section{ABSTRACT}

Whey protein concentrate (WPC) is often subjected to heat treatment during industrial processing, resulting in protein denaturation and loss of protein bioactivity. We hypothesized that WPC samples subjected to different degrees of thermal processing are associated with different levels of bioactive proteins and effects on proliferation and immune response in intestinal epithelial cells (IEC). The results showed that low-heattreated WPC had elevated levels of lactoferrin and transforming growth factor- $\beta 2$ compared with that of standard WPC. The level of aggregates depended on the source of whey, with the lowest level being found in WPC derived from acid whey. Following acid activation, WPC from acid whey enhanced IEC proliferation compared with WPC from sweet whey or nonactivated WPC. Low-heat-treated WPC from acid whey induced greater secretion of IL-8 in IEC than either standard WPC from acid whey or low-heat-treated WPC from sweet whey. Following acid activation (to activate growth factors), low-heat-treated WPC from sweet whey induced higher IL-8 levels in IEC compared with standard WPC from sweet whey. In conclusion, higher levels of bioactive proteins in low-heat-treated WPC, especially from acid whey, may enhance proliferation and cytokine responses of IEC. These considerations could be important to maintain optimal bioactivity of infant formulas, including their maturational and immunological effects on the developing intestine.

Key words: immunomodulation, milk protein, whey protein concentrate

\section{INTRODUCTION}

Mother's milk is generally accepted as the optimal diet for newborn infants and it is known to protect

Received June 15, 2015.

Accepted October 24, 2015

${ }^{1}$ Corresponding author: dcha@food.ku.dk the intestine from infection and inflammation (Kelley, 2012; Chatterton et al., 2013). Breastfeeding is not always possible and infant formula based on bovine milk is often fed to a proportion of infants, including highly sensitive hospitalized preterm infants (Merewood et al., 2006). Unfortunately, intake of milk formula increases the incidence of severe intestinal complications, including necrotizing enterocolitis (NEC), in preterm infants (Donovan, 2006; Boyd et al., 2007). The fact that formula feeding is inferior to breastfeeding in both preterm and term infants may be explained in part by a lower intake of bioactive proteins, resulting from the necessary processing technology applied during the manufacture of formula products.

Whey protein concentrate (WPC) is a common protein source used in infant formula manufacture (de Wit, 1998). It is commonly produced from sweet whey, which is a byproduct of casein coagulation by addition of chymosin to bovine milk (Li et al., 2013). However, due to the presence of lactic acid bacteria and calcium ions, industrial sweet whey is often pasteurized to reduce bacterial content, which may lead to a higher degree of electrostatic interaction between proteins due to the presence of divalent calcium ions (Havea et al., 2002). In contrast, caseins from bovine milk can be precipitated by adjusting the $\mathrm{pH}$ to 4.6 , which results in a soluble fraction called acid whey. Both whey types can be further processed by pasteurization and various filtration steps to increase the protein content before spray-drying to obtain the final WPC product in a powdered form ( $\mathrm{Li}$ et al., 2013). Whey protein concentrate consists of major whey proteins, including $\alpha$-LA, $\beta$-LG, and BSA; several immunologically active proteins such as lactoferrin $(\mathbf{L F})$, lactoperoxidase (LP), and immunoglobulins (Havea et al., 2002; Chatterton et al., 2004); and important growth factors, including transforming growth factor $\beta$ (TGF- $\beta$ ) and insulin-like growth factor (Hering et al., 2011; Chatterton et al., 2013). Different TGF- $\beta$ types in milk and dairy products are partly present in the latent forms, which are activated under acidic conditions or by di- 
gestive enzymes, thereby releasing the bioactive form. In addition, TGF- $\beta$ s are stable under intestinal digestion and able to exert protective effects in the small intestine (Khalil, 1999; Nakamura et al., 2009; Nabil et al., 2011). Supplementation of LF and TGF- $\beta 2$ to infant formulas has shown benefits in preventing intestinal inflammation in several animal models of newborn infants (Togawa et al., 2002; Maheshwari et al., 2011). In preterm infants, LF alone reduces late-onset sepsis, and the combination of LF and probiotics decreases both late-onset sepsis and incidence of NEC (Manzoni et al., 2009). Transforming growth factor- $\beta 2$ suppresses proinflammatory cytokine production in macrophages of the preterm intestine, and oral administration of TGF- $\beta 2$ protects mice from experimental NEC (Maheshwari et al., 2011). On the other hand, moderate levels of the proinflammatory cytokine IL-8 secreted by the immature intestine may be beneficial in terms of triggering intestinal repair and immune response toward the presence of bacteria (Nguyen et al., 2014a).

Reduced thermal processing of infant formula has been shown to enhance intestinal maturation and maintain moderate levels of the proinflammatory cytokine IL-8 during the first days of life in preterm pigs ( $\mathrm{Li}$ et al., 2013), and these effects may be explained by the presence of higher amounts of bioactive proteins in the diet. To a variable degree, protein bioactivity is destroyed during thermal processing of bovine milk such as pasteurization and spray-drying, which facilitate protein denaturation and aggregation (Elfstrand et al., 2002; Anandharamakrishnan et al., 2008; Ewaschuk et al., 2011). Such effects have been reported to occur for immunoglobulins (Elfstrand et al., 2002), LF (Brisson et al., 2007), and TGF- $\beta$ (Elfstrand et al., 2002; Akbache et al., 2011).

We hypothesized that gentle thermal processing of WPC preserves high levels of bioactive components, such as LF and TGF- 32 , and that this enhances the proliferative and immunomodulatory effects of WPC in intestinal epithelial cells (IEC). We investigated the protein composition of WPC products prepared from 4 different types of thermal processing. The effects of WPC products on cell proliferation and proinflammatory cytokine secretion were investigated in porcine IEC to elucidate the role of different thermal processing on milk protein bioactivity.

\section{MATERIALS AND METHODS}

\section{Materials and Reagents}

Four WPC (Table 1) produced under different thermal processing conditions and whey sources were tested, such that the effects of more gentle thermal processing conditions could be compared with standard conditions. The total protein content in all WPC was analyzed by Eurofins Steins Laboratorium (Vejen, Denmark). Standard WPC from acid whey (A-WPC) and sweet whey (S-WPC) were produced at Arla Foods Ingredients (AFI, Viby, Denmark) using standard pasteurization $\left(72-75^{\circ} \mathrm{C}, 15 \mathrm{~s}\right)$ and spray drying (inlet and outlet temperatures of $180-220^{\circ} \mathrm{C}$ and $83-90^{\circ} \mathrm{C}$, respectively). Low-heat-treated WPC from acid whey (LA-WPC) was also produced at AFI using similar processing conditions as A-WPC but with fewer steps of pasteurization and low-temperature spray-drying (Table 1). Low-heat-treated WPC from sweet whey (LS-WPC) was produced in the dairy pilot plant of the University of Copenhagen (Denmark) under minimal processing conditions (temperature $<40^{\circ} \mathrm{C}$ ), and freeze-drying was applied instead of spray-drying before sterilization by $\gamma$-irradiation (at $50 \mathrm{~Gy}$ ).

Advanced Dulbecco's modified Eagle medium (DMEM), reagents for cell culture, and polyvinylidene

Table 1. Whey protein concentrate (WPC) powders used in this study and their specifications

\begin{tabular}{|c|c|c|c|c|}
\hline Material & Abbreviation & Whey source & $\begin{array}{l}\text { Protein content } \\
\quad(\% \mathrm{wt} / \mathrm{wt})\end{array}$ & Heat treatment characteristics ${ }^{1}$ \\
\hline Bioactive WPC & LA-WPC & Acid whey & 61 & $\begin{array}{l}\text { Standard milk pasteurization; no pasteurization of acid } \\
\text { whey, low inlet }\left(160^{\circ} \mathrm{C}\right) \text { and outlet temperature }\left(78^{\circ} \mathrm{C}\right) \\
\text { during spray-drying. }\end{array}$ \\
\hline Low-heat-treated WPC & LS-WPC & Sweet whey & 80 & $\begin{array}{l}\text { No pasteurization of milk or sweet whey but } \\
\gamma \text {-irradiated }(50 \mathrm{~Gy}) \text { after freeze-drying. }\end{array}$ \\
\hline Lacprodan DI- $8090^{2}$ & S-WPC & Sweet whey & 78 & $\begin{array}{l}\text { Standard pasteurization of milk and whey; standard } \\
\text { spray-drying. }\end{array}$ \\
\hline
\end{tabular}

${ }^{1}$ Standard pasteurization $=72-75^{\circ} \mathrm{C}$ for $15 \mathrm{~s}$; standard spray-drying $=$ an inlet temperature of between 180 and $220^{\circ} \mathrm{C}$ and an outlet temperature of between 83 and $90^{\circ} \mathrm{C}$.

${ }^{2}$ Arla Foods Ingredients (Viby, Denmark). 
difluoride (PVDF) membranes for Western blot were from Life Technologies (Naerum, Denmark). Lipopolysaccharide (from Escherichia coli O26:B6) and materials for SDS-PAGE were from Sigma-Aldrich (Brøndby, Denmark). Primary antibody against TGF- $\beta 2$ (Sc-90) was purchased from Santa Cruz Biotechnology (Santa Cruz, CA).

\section{Protein and Aggregate Analysis by SDS-PAGE, Western Blot, and Size Exclusion Chromatography}

The WPC samples were dissolved to obtain a protein level of $1 \%(\mathrm{wt} / \mathrm{vol})$. Protein composition was analyzed by SDS-PAGE under both nonreducing and reducing conditions as described previously (Chatterton et al., 2004). For reducing conditions, $50 \mathrm{~m} M$ dithiothreitol and $10 \mathrm{~m} M$ iodoacetamide were used for reduction and alkylation, respectively. Equal amounts of protein $(10 \mu \mathrm{g})$ from each WPC were separated using 15\% Tris-glycine SDS-PAGE and stained with Coomassie Brilliant Blue R-250. Bands from gels were analyzed by densitometry using Phoretix 1D software (Totallab, Newcastle upon Tyne, UK). Protein standards ( $\alpha$-LA, $\beta$-LG, BSA, and LF) were run to confirm the identity of protein bands. Transforming growth factor- $\beta 2$ content in the 4 WPC was analyzed as TGF- $\beta 2$ monomer using Western blot following SDS-PAGE under reducing conditions as indicated previously (Chatterton et al., 2004). Briefly, proteins from WPC solutions were resolved by SDS-PAGE under reducing conditions, transferred onto PVDF membranes (Life Technologies), and probed with TGF- $\beta 2$ antibody, followed by secondary antibody detection of TGF- $\beta 2$ in monomer form (12.5 kDa) by chemiluminescence.

For analysis of aggregate content, $1 \%$ (wt/vol) protein solutions at neutral $\mathrm{pH}$ were centrifuged at 16,000 $\times g$ for $45 \mathrm{~min}$. The pellets were washed and resuspended in $100 \mu \mathrm{L}$ of Milli-Q (Millipore, Billerica, MA) water before SDS-PAGE analysis under both nonreducing and reducing conditions. Protein fractions in WPC solutions were also analyzed by size exclusion chromatography (SEC) after centrifugation $(10,000 \times g$ for $30 \mathrm{~min})$ and filtration $(0.45 \mu \mathrm{m})$ to remove aggregates. Subsequently, $100 \mu \mathrm{L}$ of sample was analyzed using a fast protein liquid chromatography (FPLC) system with a Superose 12-10/300 GL column (dimensions $1 \times 30 \mathrm{~cm}$, particle size $10 \pm 2 \mu \mathrm{m}$, GE Healthcare, Brøndby, Denmark). Proteins were separated in $10 \mathrm{mM}$ Tris-HCl buffer containing $150 \mathrm{~m} M \mathrm{NaCl}(\mathrm{pH}$ 7) at a flow rate of $0.5 \mathrm{~mL} / \mathrm{min}$ for a total of $60 \mathrm{~min}$. Eluted proteins were detected by UV absorbance at $280 \mathrm{~nm}$. The profiles of the chromatograms were subsequently integrated to obtain peak areas of the corresponding proteins and fractions.

\section{Cell Culture}

Porcine intestinal epithelial cells (PsIc1) from a 6-moold pig (Bionutritech, Lunel, France) at passage 5 to 25 were cultured in advanced DMEM medium supplemented with $2 \%$ heat-inactivated fetal bovine serum, $40 \mathrm{U} / \mathrm{mL}$ penicillin, $40 \mu \mathrm{g} / \mathrm{mL}$ streptomycin, and $2 \mathrm{mM}$ Glutamax (Life Technologies) at $37^{\circ} \mathrm{C}$ and $5 \% \mathrm{CO}_{2}$. The WPC samples used for cell culture were prepared in endotoxin-free water to reach $1 \%$ (wt/vol) protein, centrifuged (at 10,000 $\times g$ for $30 \mathrm{~min}$ ), and sterile filtered $(0.2 \mu \mathrm{m})$. In some experiments, WPC solutions were adjusted to $\mathrm{pH} 2.0$ and stirred for $1 \mathrm{~h}$ before final $\mathrm{pH}$ adjustment to 7.0 , followed by centrifugation and filtration. Acid activation was performed to release the active forms of several growth factors including TGF- $\beta$ (Saito et al., 1993; Nakamura et al., 2009). The WPC samples were then diluted at appropriate protein concentrations ( 0.1 and $1 \mathrm{~g} / \mathrm{L}$ ) with serum-free medium for subsequent assays.

\section{Cell Proliferation Assay}

Cells were plated on 96 -well plates $\left(100 \mu \mathrm{L}, 5 \times 10^{3}\right.$ cells/well) and allowed to attach for $24 \mathrm{~h}$ before treatment with the $4 \mathrm{WPC}$ at protein concentrations of 0.1 and $1 \mathrm{~g} / \mathrm{L}$ with and without acid activation for another $48 \mathrm{~h}$ in serum-free medium. Cell proliferation was quantified by Celltiter 96 Aqueous One Solution Cell Proliferation Assay (Promega, Stockholm, Sweden). Briefly, each well was mixed with $20 \mu \mathrm{L}$ of Celltiter 96 Aqueous One reagent containing MTS tetrazolium [3-(4,5-dimethylthiazol-2-yl)-5-(3-carboxymethoxyphenyl)-

2-(4-sulfophenyl)-2H-tetrazolium] compound, which is reduced by NADH or NADPH produced by active cells. The formation of a dark yellow formazan product was measured (absorbance at $490 \mathrm{~nm}$ ) following $2 \mathrm{~h}$ of incubation. The proliferation of WPC-treated cells was quantified as the absorbance percentage relative to that from cells incubated in medium with serum $(2 \%$ fetal bovine serum).

\section{Effect of WPC and LPS on Cytokine Secretion}

Before the cytokine assay, cell viability was tested to determine if any WPC treatments caused cell death, which may influence the number of cytokine-secreting cells. Cells at 90 to $95 \%$ confluency on 96 -well plates were treated with WPC samples at $0.1 \mathrm{~g} / \mathrm{L}$ protein for $24 \mathrm{~h}$. Thereafter, cell viability in each well was measured by CellTiter 96 AQueous One Solution Assay.

For the cytokine assay, cells were seeded on 24-well plates, cultured until $90 \%$ confluency, and then serum starved for $24 \mathrm{~h}$. Cells were then treated with LPS at 1 
$\mu \mathrm{g} / \mathrm{mL}$ or WPC $(0.1 \mathrm{~g} / \mathrm{L}$ protein $)$ with or without acid activation for $24 \mathrm{~h}$. The control was cells in serum-free medium alone. Thereafter, supernatants were collected for analysis of IL- 8 and IL- 6 by ELISA (R\&D systems, Abingdon, UK). The quantified cytokine levels following treatments from each cell passage were normalized as fold changes compared with the control.

\section{Statistical Analysis}

Experiments were performed in triplicate. Data are reported as means \pm standard error of the mean (SEM). Comparisons between groups were performed using ANOVA and Tukey's or Bonferroni's test in GraphPad Prism 5.0 (GraphPad Software Inc., La Jolla, CA,). Significant differences were considered at $P$-values $<$ 0.05 .

\section{RESULTS}

\section{Effect of Heat Treatment on Protein Content of WPC}

The composition of major proteins in the $4 \mathrm{WPC}$ is illustrated in Figure 1A under both nonreducing and reducing conditions. Under nonreducing conditions, proteins with their original disulfide bonds and aggregates were observed, whereas under reducing conditions, all disulfide bonds in both the proteins and their aggregates were cleaved, leading to more intensive staining of corresponding proteins, as previously described (Gezimati et al., 1996; Havea et al., 2002). As relatively quantified (Figure $1 \mathrm{~B}), \mathrm{LF}(\sim 80 \mathrm{kDa})$ was the most abundant in LA-WPC, followed by LS-WPC (2.7-fold lower than in LA-WPC; $P<0.05$ ), but LF was not detected in the 2 standard heat-treated WPC (A-WPC and S-WPC). In addition, the concentrations of $\alpha$-LA $(\sim 14.2 \mathrm{kDa})$ and $\beta$-LG $(\sim 18.4 \mathrm{kDa})$ were more dependent on whey source than on heat treatment: LA-WPC and A-WPC had similar levels of $\beta-\mathrm{LG}$ and $\alpha$-LA, whereas LS-WPC and S-WPC had similar concentrations of $\beta$-LG. In contrast, the 2 WPC from acid whey had greater concentrations of $\alpha-\mathrm{LA}$ and $\beta-\mathrm{LG}$ than those from sweet whey (1.1- to 1.3-fold; $P<0.05$ ).

\section{Effect of Heat Treatment on the TGF- $\beta 2$ Content of WPC}

The concentration of TGF- $\beta 2$, measured as TGF- $\beta 2$ monomer $(12.5 \mathrm{kDa})$, differed between the $4 \mathrm{WPC}$ (Figure 2, $P<0.05$ ), with the levels being highest in LS-WPC, followed by LA-WPC (1.7-fold lower) whereas negligible TGF- $\beta 2$ was detected in A-WPC and S-WPC (20-30\% compared with that in LS-WPC).

\section{Protein Composition Analyzed by SEC}

To confirm SDS-PAGE data, protein contents were also analyzed by SEC. Five distinct peaks were observed including a high-molecular-weight fraction (peak 1), co-elution of immunoglobulins, LF, LP, BSA (peak 2), $\beta$-LG (peak 3), $\alpha$-LA (peak 4), and small peptides (peak 5; Figure 3A). Identification of specific proteins was based on the calibration of the chromatographic column with purified standards. Similar to SDS-PAGE data, LA-WPC and A-WPC had higher concentrations of $\alpha$-LA and $\beta$-LG than LS-WPC and S-WPC (1.2- to 1.3-fold, $P<0.05$ ), and no effect of heat treatment was observed (Figure 3B). In contrast, less-intense thermal processing markedly elevated the content of the coeluted immunoglobulins $+\mathrm{LF}+\mathrm{LP}+\mathrm{BSA}$ fraction (peak 2, 1.5- to 2.1-fold greater in low-heat-treated WPC, $P<0.05)$. In addition, the amounts of the highmolecular-weight fraction (peak 1) in the 4 WPC were similar. The content of total protein, illustrated by total peak area, was greater in LA-WPC and A-WPC than in LS-WPC and S-WPC (1.2- to 1.3-fold, $P<$ $0.05)$. As the total protein content before centrifugation and filtration was the same between the 4 WPC, differences in total peak areas indicated that the content of aggregates contained in the WPC from sweet whey was greater than that of the WPC from acid whey.

\section{Aggregates Analyzed by SDS-PAGE}

Whey source affected the levels of aggregates to a greater extent than the effect of heat treatment, with more pronounced amounts of aggregates detected by SDS-PAGE in WPC derived from sweet whey (Figure $4)$. The aggregates included all the major whey proteins such as $\alpha$-LA, $\beta$-LG, BSA, LF, and immunoglobulins. In particular, very intense bands were observed in the aggregates of S-WPC, in contrast to negligible contents of aggregates in LA-WPC and A-WPC; LSWPC had intermediate amounts. In addition, as shown in Figure 1, reducing conditions decreased the highmolecular-weight aggregate band at $250 \mathrm{kDa}$, with a concomitant increase in the amounts of LF, BSA, and immunoglobulins, indicating that these proteins are major constituents of thermally induced aggregates with covalent bonds.

\section{Effects of WPC on Cell Proliferation}

All WPC samples increased cell proliferation at 0.1 $\mathrm{g} / \mathrm{L}(P<0.01)$ but not at $1 \mathrm{~g} / \mathrm{L}$, relative to the control (Figure 5A and B). The effects of low heat treatment, acid whey, and acid activation further enhanced cell 
proliferation in some treatments. For instance, at 0.1 $\mathrm{g} / \mathrm{L}, \mathrm{LS}-\mathrm{WPC}$ resulted in higher cell proliferation than S-WPC $(P<0.05)$, and both A-WPC at $0.1 \mathrm{~g} / \mathrm{L}$ and $\mathrm{LA}-\mathrm{WPC}$ at $1 \mathrm{~g} / \mathrm{L}$ induced greater proliferation than S-WPC and LS-WPC at the same concentrations, respectively $(P<0.05)$. Acid-activated LS-WPC at $1 \mathrm{~g} / \mathrm{L}$ induced higher proliferation than that without activation $(P<0.05)$.

\section{Effects of WPC on Cytokine Secretion}

The WPC samples did not cause any marked changes in cell viability (Supplemental Figure S1; http://dx.doi. org/10.3168/jds.2015-9965), confirming no confounding factors from cell death affecting the cytokine assays. The production of the inflammatory cytokines IL-8 and IL-6 from IEC illustrates the ability of WPC to affect

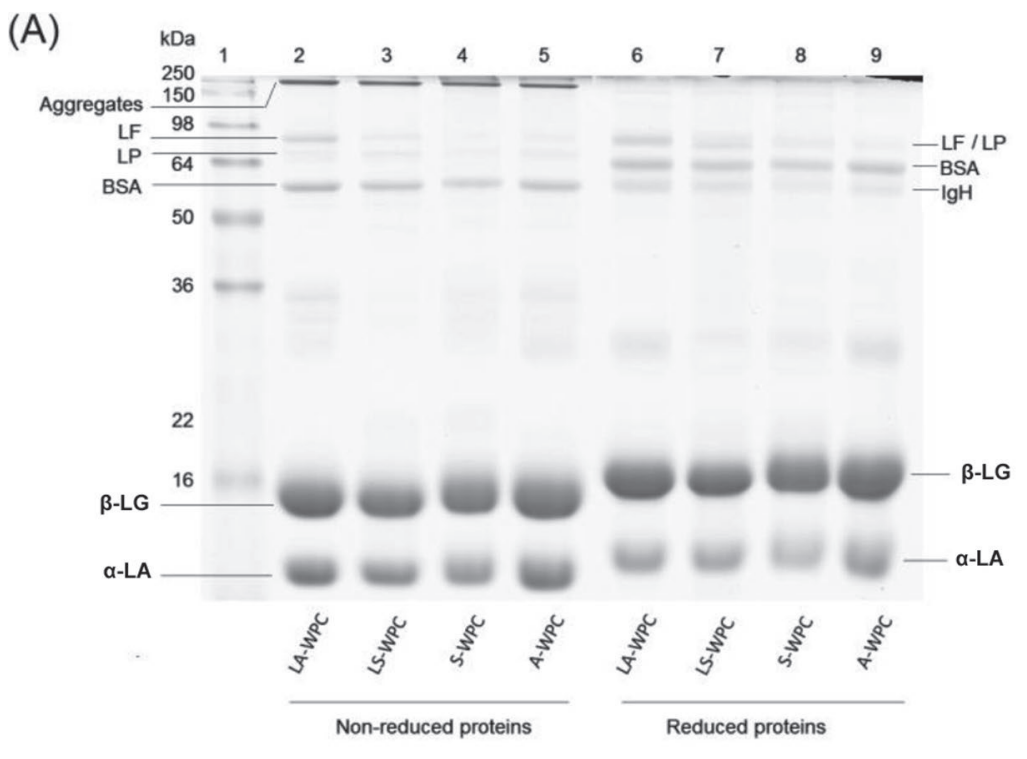

(B)

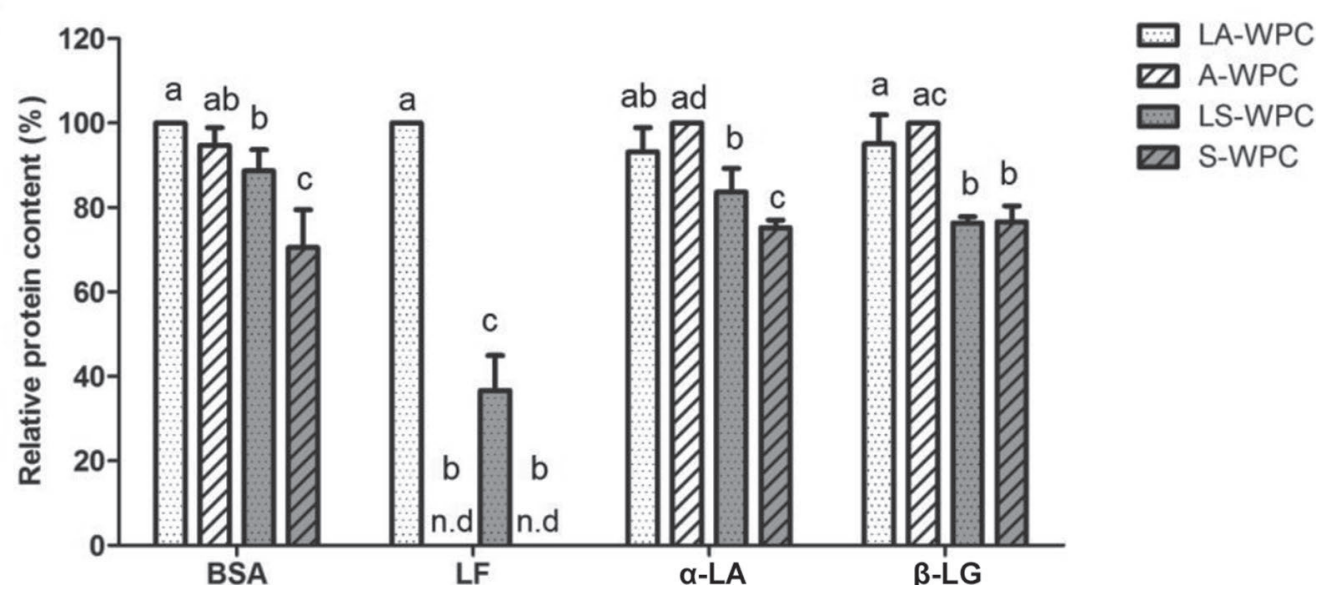

Figure 1. Protein composition of 4 whey protein concentrates (WPC) analyzed by SDS-PAGE using $15 \%$ polyacrylamide gels under nonreducing and reducing conditions. Gels were stained with Coomassie Brilliant Blue R-250. (A) Representative SDS-PAGE gel; LF = lactoferrin; LP = lactoperoxidase; IgH = heavy chain of immunoglobulin obtained under reducing conditions. (B) Quantification by densitometry of BSA, LF, $\alpha$-LA, and $\beta$-LG in nonreducing conditions. For each protein, data were normalized to the highest band volume (100\%) in the 4 WPC. Values are means \pm SEM $(n=3)$. Values of each protein not sharing the same letters are significantly different $(P<0.05)$. LA-WPC $=$ low-heat-treated WPC from acid whey, LS-WPC $=$ low-heat-treated WPC from sweet whey, S-WPC $=$ standard WPC from sweet whey, and A-WPC $=$ standard WPC from acid whey; n.d. = not detected. 
immune responses in intestinal cells and possibly in the small intestine. The PsIc1 cells (IEC) were not sensitive to individual treatment of LPS $(0.1-1 \mu \mathrm{g} / \mathrm{mL})$ to induce IL-8 (1.1-fold increase of IL- $8, P>0.05$, data not shown). However, treatment with WPC increased IL-8 secretion to a different extent. This indicates that protein components in WPC may play a role in initiating specific immune responses, which are not related to the endotoxin contents of these products. Low-heat-treated WPC, especially LA-WPC, tended to induce greater levels of IL-8 compared with other WPC (Figure 5C). In particular, within nonactivated WPC, LA-WPC but not A-WPC elevated IL-8 levels compared with the control. Levels of IL-8 induced by LA-WPC were greater than those induced by LS-WPC (1.3-fold, $P$ $<0.05)$. Among acid-activated WPC, IL-8 levels were greater following treatment with LS-WPC compared

\section{(A)}

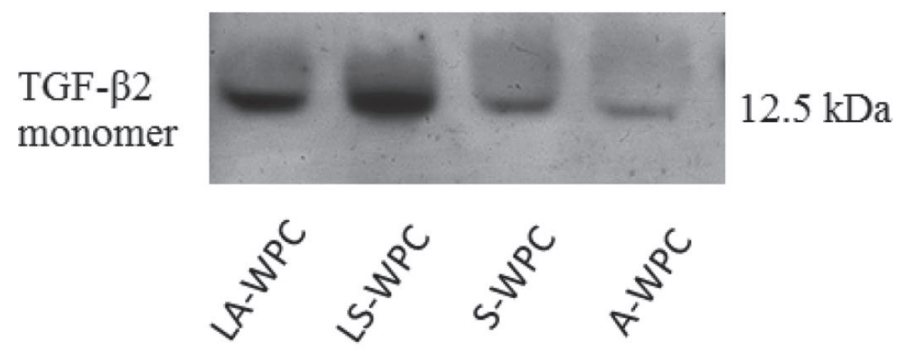

(B)

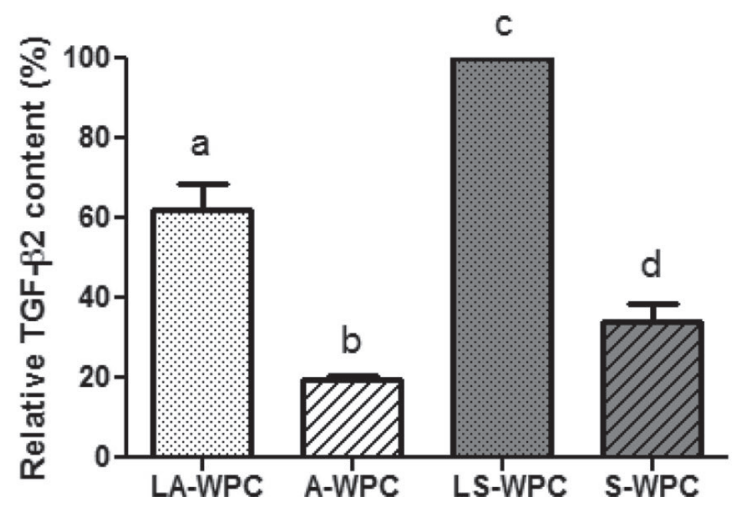

Figure 2. Transforming growth factor (TGF)- $\beta 2$ content of whey protein concentrates (WPC), demonstrated as a monomer band of $12.5 \mathrm{kDa}$. (A) Representative Western blot of TGF- $\beta 2$ monomer in LA-WPC, LS-WPC, S-WPC, and A-WPC, respectively. (B) Quantification by densitometry of TGF- $\beta 2$. Data were normalized to the highest band volume (100\% in LS-WPC). Values are means \pm SEM $(\mathrm{n}=3)$. Values of each protein not sharing the same letters are significantly different $(P<0.05)$. LA-WPC $=$ low-heat-treated WPC from acid whey, LS-WPC = low-heat-treated WPC from sweet whey, $\mathrm{S}-\mathrm{WPC}=$ standard WPC from sweet whey, and $\mathrm{A}-\mathrm{WPC}=$ standard WPC from acid whey. with S-WPC (1.3-fold, $P<0.05)$. Furthermore, acid activation enhanced IL-8 secretion for LS-WPC (1.3fold, $P<0.05)$. The profile of IL-6 secretion was similar in all WPC treatments (Figure 5D).

\section{DISCUSSION}

Pasteurization and spray drying are 2 important processes applied during the manufacture of WPC (de la Fuente et al., 2002). However, these processes result in protein denaturation and aggregation, causing a loss of protein bioactivity, especially for heat-labile proteins such as LF and immunoglobulins (Elfstrand et al., 2002; Anandharamakrishnan et al., 2008; Ewaschuk et al., 2011). In addition to heat treatment, the content and activity of milk factors such as IGF and TGF- $\beta$ are dependent on other manufacturing processes such as whey separation and filtration (Elfstrand et al., 2002). Gentler thermal processing could be a more economical way to enhance the bioactivity and quality of infant formula ingredients than supplementation with purified fractions or recombinant proteins. In this study, the low temperatures applied during spray drying of LA-WPC or the combination of $\gamma$-irradiation and freeze drying during processing of LS-WPC provided gentler alternatives to conventional thermal treatments and would be expected to result in greater retention of bioactive proteins. Indeed, LF and TGF- $\beta 2$ were retained at greater levels in low-heat-treated WPC than in standard WPC. Other proteins such as BSA and immunoglobulins were also retained at higher levels in LA-WPC and LS-WPC, based on SEC data. Furthermore, more aggregates were observed in the WPC derived from sweet whey, irrespective of whether they were produced by low-heat or standard thermal treatments. This also explains the higher concentrations of nonaggregated $\alpha-\mathrm{LA}$ and $\beta$-LG in LA-WPC and A-WPC due to greater levels of these proteins in the aggregates of LS-WPC and S-WPC. Recently, we used LA-WPC and LS-WPC to test the protective effects in vulnerable newborn preterm pigs, and we demonstrated that these 2 low-heat-treated WPC induced moderate levels of IL-8, enhanced carbohydrate absorption, and decreased intestinal permeability ( $\mathrm{Li}$ et al., 2013). These beneficial effects of low-heat-treated WPC in vivo further confirm that optimal infant formula processing preserves more bioactive proteins, such as LF and TGF- $\beta 2$, as we have shown in the current study, resulting in a greater capacity to protect the immature intestine of newborns.

Lactoferrin is a multifunctional protein with potential protective effects against gastrointestinal diseases in newborn infants (Manzoni et al., 2009). However, it is heat-labile and its structure is denatured by even mild pasteurization at $63^{\circ} \mathrm{C}$ for $30 \mathrm{~min}$, as applied to donor 

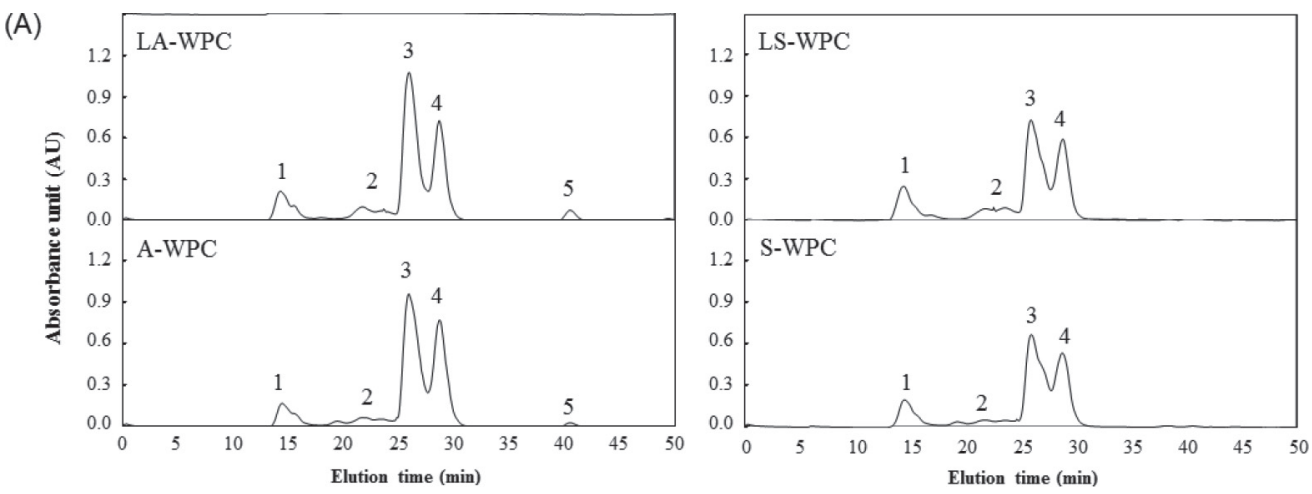

(B)

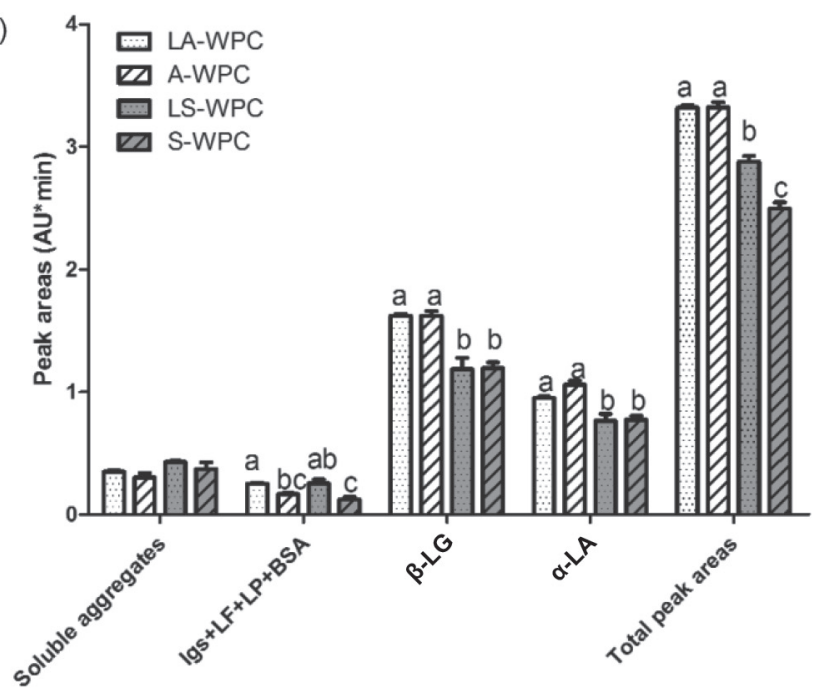

Figure 3. Main fractions separated by size exclusion chromatography of the 4 whey protein concentrates (WPC) following removal of aggregates. (A) Representative chromatogram: peak $1=$ high-molecular-weight fraction, peak $2=$ immunoglobulins (Igs) + lactoferrin (LF) + lactoperoxidase (LP) + BSA, peak $3=\beta$-LG, peak $4=\alpha$-LA, peak $5=$ peptides. (B) Quantification of peak areas obtained from (A). Values are means \pm SEM $(n=3)$. Values of each group not sharing the same letters are significantly different $(P<0.05)$. LA-WPC $=$ low-heat-treated WPC from acid whey, LS-WPC = low-heat-treated WPC from sweet whey, S-WPC = standard WPC from sweet whey, and A-WPC $=$ standard WPC from acid whey. AU = arbitrary units.

human milk (loss of 57-80\%; Ewaschuk et al., 2011). Our data confirmed this with a higher LF content in low-heat-treated WPC. Furthermore, LF content was higher in LA-WPC than in LS-WPC, even though the latter did not receive any thermal treatments during processing. This was a surprising finding and further investigations regarding the effect of freeze drying and $\gamma$-radiation on LF content would be important.

Transforming growth factor- $\beta 2$ is an anti-inflammatory protein that prevents experimental intestinal inflammation in young mice (Maheshwari et al., 2011). It is present in bovine raw milk as the second most abundant growth factor after IGF-1, but during the skimming of milk, whey separation, and the subsequent pasteurization steps applied during WPC processing, TGF- $\beta 2$ interacts with other components and remains in WPC at negligible levels (McPherson and Wagner,
2001; Akbache et al., 2011). The LS-WPC sample, which did not receive any heat treatment during its processing, had the highest content of TGF- $\beta 2$. Likewise, LAWPC, which was produced with no pasteurization of whey and low-temperature spray-drying, had a higher TGF- $\beta 2$ content than A-WPC and S-WPC. Therefore, the greater amounts of LF and TGF- $\beta 2$ in the formulas that are gently processed may exert similar effects against intestinal inflammation in newborn neonates as previously described with LF and TGF- $\beta 2$-enriched infant formula (Manzoni et al., 2009; Maheshwari et al., 2011).

Analysis of proteins and aggregates by SDS-PAGE and SEC indicate that the source of whey is the main factor responsible for aggregate formation in WPC. The WPC from sweet whey had greater aggregate contents than WPC from acid whey, irrespective of the degree 
of thermal treatment applied (e.g., low versus standard heat treatments). This may be because of the higher mineral content present in sweet whey (such as $\mathrm{Ca}^{2+}$ and $\mathrm{Mg}^{2+}$ ) compared with acid whey, as previously reported (Havea et al., 2002). These ions often form bridges between negatively charged proteins by electrostatic interactions to facilitate more aggregation. Even though the bioactivity of protein aggregates present in WPC have not been elucidated, oral intake of aggregates has been shown to affect intestinal immunity by promoting $\mathrm{T}$ helper 2 (Th2)-associated responses and cytokine release in Peyer's patches (Roth-Walter et al., 2008). Further investigations regarding the effects of aggregation on intestinal immunity are needed.

Intestinal cell proliferation was measured in part to reflect the process of intestinal maturation and growth in infants. The WPC from acid whey exerted greater proliferative effects in PsIc1 cells (greater in A-WPC than S-WPC at $0.1 \mathrm{~g} / \mathrm{L}$ ), whereas heat treatment did not affect proliferation. The lower aggregate contents, and thereby the greater levels of bioactive proteins, in WPC from acid whey may explain these effects. However, it is difficult to evaluate the ability of a mixture of various proteins because individual proteins affect proliferation to different extents (Planchon et al., 1994; Jiang et al., 2011). In addition, we showed that these proliferative effects were dose-dependent. This indicates that during the rapid period of growth of newborn infants, they require specific supplementation of nutrients and may need to consume formulas with appropriate protein enrichment to maintain adequate stimulation of intestinal growth. This may also be an important way to facilitate protection against diseases such as NEC in preterm infants that are not breastfed.

The observed cellular secretion of proinflammatory cytokines after exposure to different WPC may indicate the differential involvement of whey proteins in immune responses in IEC. Following the different milk processing steps (e.g., pasteurization, microfiltration, and ultrafiltration), bacteria and bacterial products with low molecular weight $(<5 \mathrm{kDa}$, derived from the initial raw milk) are likely removed. We selected PsIc1, a cell line that is not sensitive to LPS-induced IL-8 secretion, to test the effects of WPC without any influence of its endotoxin content. Our data suggest that both heat treatment and whey type affect IL-8 secretion, as IL-8 levels secreted from cells treated with LA-WPC were higher than from LS-WPC exposure

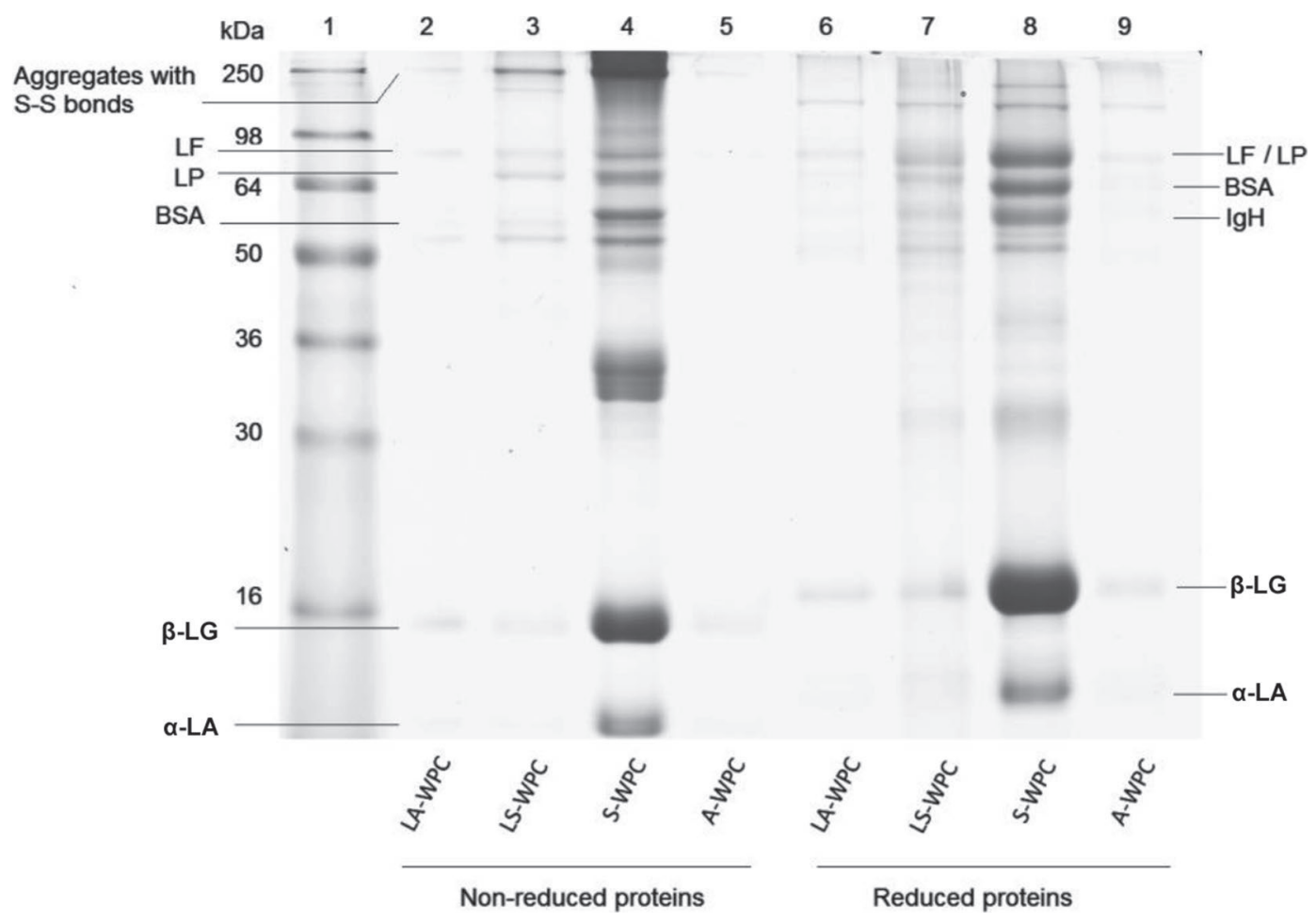

Figure 4. Aggregate content of whey protein concentrates (WPC) analyzed by SDS-PAGE using 15\% polyacrylamide gels under nonreducing and reducing conditions. S-S = disulfide bond; $\mathrm{IgH}=$ heavy chain of immunoglobulin obtained under reducing conditions; $\mathrm{LF}=$ lactoferrin; $\mathrm{LP}$ $=$ lactoperoxidase; LA-WPC = low heat-treated WPC from acid whey; LS-WPC = low heat-treated WPC from sweet whey; S-WPC $=$ standard WPC from sweet whey; and A-WPC = standard WPC from acid whey. 
and tended to be higher relative to A-WPC exposure. Moreover, LA-WPC induced the greatest secretion of IL-8, implying that the combination of low heat treatment and acid whey allows retention of the highest amount of bioactive proteins and the greatest effects on IEC. This hypothesis is supported by the observation of greater levels of LF, TGF- $\beta 2$, and immunoglobulins in low-heat-treated WPC, and lower aggregate contents in WPC derived from acid whey. Previously, we observed that LF (Nguyen et al., 2014b) and TGF- 32 in synergy with LPS (Nguyen et al., 2014a) induce IL-8 secretion in PsIc1 cells. Greater concentrations of LF and other minor proteins such as TGF- $\beta 2$ in LA-WPC may be key factors in whey that contribute to stimulate IL-8 secretion. These effects could also occur in vivo, as LF and TGF- $\beta 2$ are relatively stable under gastrointestinal conditions in newborn infants (Chatterton et al., 2004; Nabil et al., 2011). Furthermore, the increased IL-8 release from LS-WPC after acid activation indicates that activation of growth factors from their latent forms
(A)

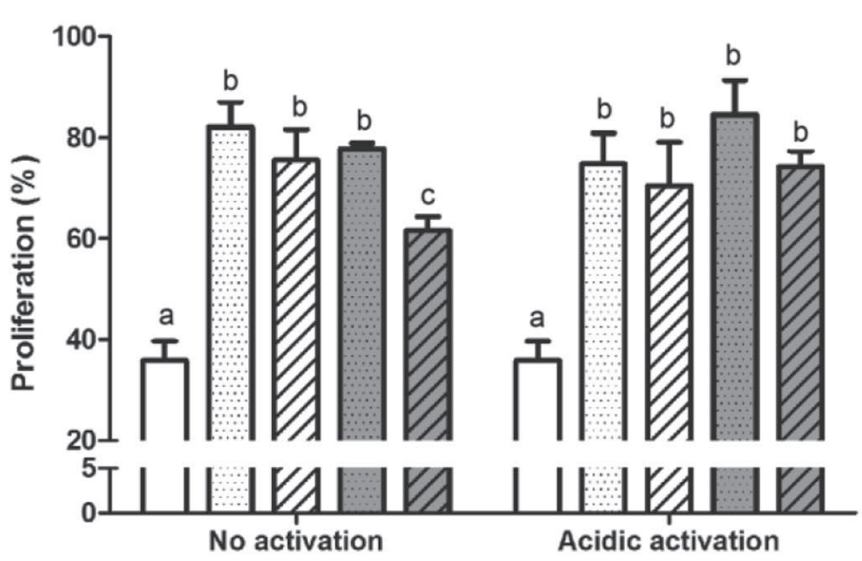

(C)

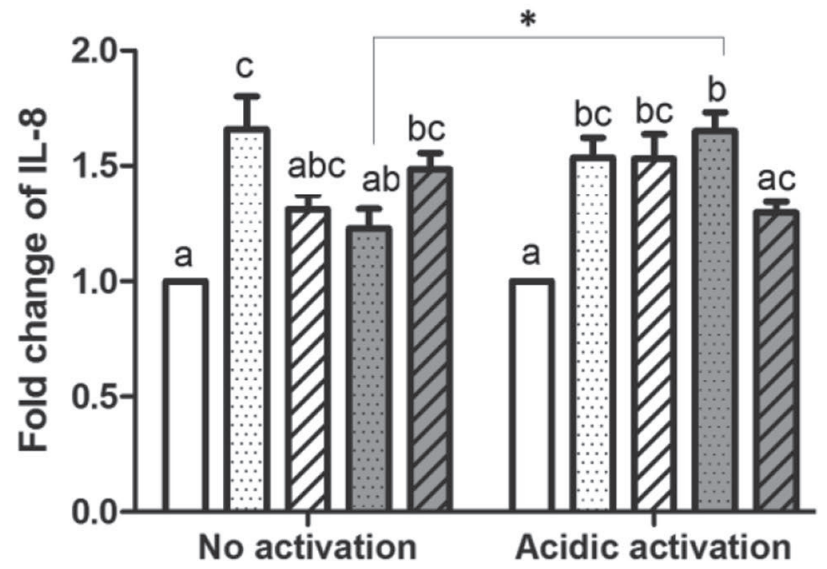

LS-WPC

S-WPC

(B)

Proliferation - WPC $1 \mathrm{~g} / \mathrm{L}$

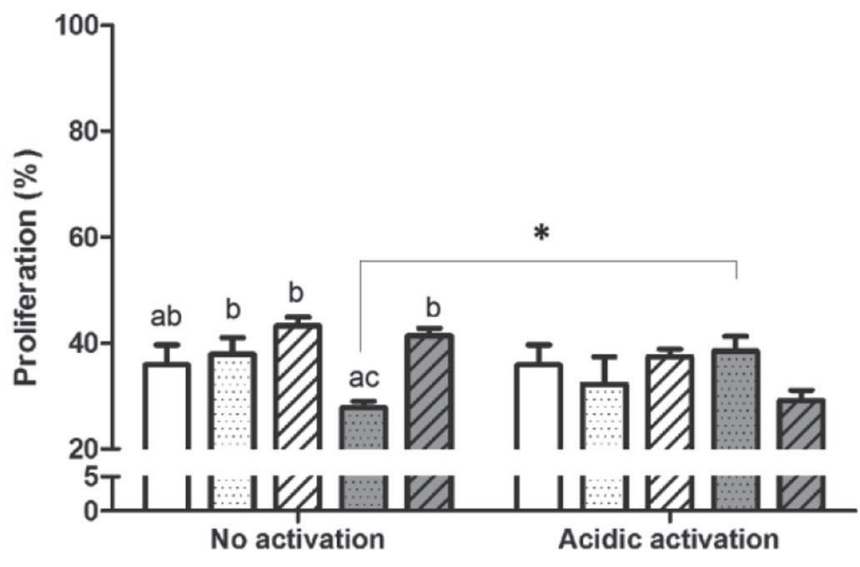

(D)

IL-6 secretion - WPC $0.1 \mathrm{~g} / \mathrm{L}$

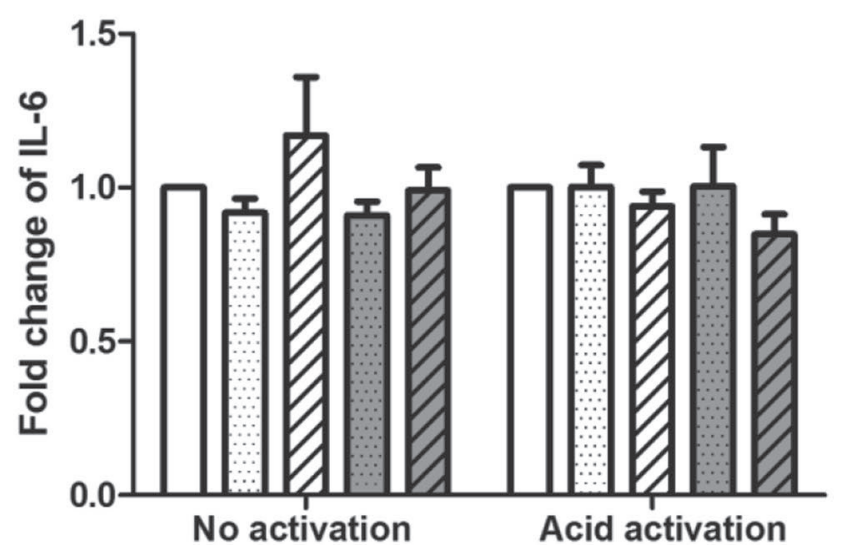

Figure 5. Effect of whey protein concentrates (WPC) on proliferation and cytokine secretion of PsIc1 cells. For proliferation, cells were seeded at $5 \times 10^{3}$ cells/well in 96-well plates for $24 \mathrm{~h}$ before stimulation by either non-acid-activated or acid-activated WPC at $0.1 \mathrm{~g} / \mathrm{L}$ (A) or 1 $\mathrm{g} / \mathrm{L}$ (B) for $48 \mathrm{~h}$ in serum-free medium. Absorbance values were normalized in percentage compared with no cell treatment (0\%) and cells grown in serum medium (100\%). For cytokine secretion, cells were treated with nonactivated or acid-activated WPC at $0.1 \mathrm{~g} / \mathrm{L}$ for $24 \mathrm{~h}$. Supernatants were analyzed by ELISA for IL-8 (C) and IL-6 (D). Values are means \pm SEM $(\mathrm{n}=3)$. Treatments among each group of nonactivation or acidic activation not sharing common letters were significantly different $(P<0.05)$. ${ }^{*} P<0.05$, between nonactivated and acid-activated WPC. LA$\mathrm{WPC}=$ low-heat-treated WPC from acid whey, LS-WPC = low-heat-treated WPC from sweet whey, S-WPC $=$ standard WPC from sweet whey, and $\mathrm{A}-\mathrm{WPC}=$ standard WPC from acid whey. 
contributes to the regulation of immune responses in the intestine. It is noteworthy that IL-8 secretion in IEC induced by LA-WPC was higher than that induced by LS-WPC but this difference was not observed after acid activation. This finding suggests that the processing of acid whey during industrial manufacture of WPC may lead to higher levels of growth factors in their active forms in LA-WPC, whereas some growth factors may remain in their latent forms in LS-WPC (without acid treatment). This is also in line with greater IL-8 levels induced by activated LS-WPC than by S-WPC, probably due to the higher levels of latent forms of growth factors in LS-WPC becoming physiologically active following acid treatment.

Overall, our study demonstrated thermal processing as the critical aspect for maintaining the bioactivity of WPC. Low-heat-treated WPC have greater amounts of bioactive proteins such as LF and TGF- $\beta 2$. The bioactive forms of proteins and growth factors present in low-heat-treated WPC may induce greater proliferation and an enhanced immune response in IEC. Gentle processing of acid whey may be optimal for WPC production, because this WPC had the lowest aggregate contents and highest levels of active forms of bioactive proteins. In this study, we focused on 4 WPC products derived from different batches of raw milk. Future studies with WPC products manufactured from the same batch of raw milk may further confirm the effects of gentle processing on protein bioactivity. It is also important to note the limitation of cell culture experiments with nonsterile food products such as WPC. Whey protein concentrates may contain bacterial products that can affect experimental outcomes, even though we performed a sterile filtration of WPC solutions and used the PsIc1 cell line, which is not sensitive to LPS to investigate the immunomodulatory effects of WPC. Despite these limitations, the present results, combined with those of our previous study in preterm pigs (Li et al., 2013), suggest that gently processed WPC products may help to improve the effects of formula on the developing intestine in infants.

\section{ACKNOWLEDGMENTS}

This study was supported by the grant from the Danish Dairy Research Foundation (Aarhus, Denmark). We thank Mette Viberg Østergaard (University of Copenhagen, Frederiksberg, Denmark) for setting up the protocol of the PsIc1 cell line. Y. Li was an industrial PhD student at the University of Copenhagen and employed at Arla Foods Ingredients Group P/S (Viby, Denmark). All remaining authors have no potential conflicts of interest.

\section{REFERENCES}

Akbache, A., A. Rocafi, M. Saffon, É. Lamiot, O. Moroni, S. Turgeon, C. Richard, S. F. Gauthier, and Y. Pouliot. 2011. Effect of heating on the distribution of transforming growth factor- $\beta 2$ in bovine milk. Food Res. Int. 44:28-32.

Anandharamakrishnan, C., C. D. Rielly, and A. G. F. Stapley. 2008. Loss of solubility of [alpha]-lactalbumin and [beta]-lactoglobulin during the spray drying of whey proteins. Food Sci. Technol. (Campinas.) 41:270-277.

Boyd, C. A., M. A. Quigley, and P. Brocklehurst. 2007. Donor breast milk versus infant formula for preterm infants: Systematic review and meta-analysis. Arch. Dis. Child. Fetal Neonatal Ed. 92:F169F175.

Brisson, G., M. Britten, and Y. Pouliot. 2007. Heat-induced aggregation of bovine lactoferrin at neutral pH: Effect of iron saturation. Int. Dairy J. 17:617-624.

Chatterton, D. E. W., D. N. Nguyen, S. B. Bering, and P. T. Sangild. 2013. Anti-inflammatory mechanisms of bioactive milk proteins in the intestine of newborns. Int. J. Biochem. Cell Biol. 45:1730-1747.

Chatterton, D. E. W., J. T. Rasmussen, C. W. Heegaard, E. S. S $\varnothing-$ rensen, and T. E. Petersen. 2004. In vitro digestion of novel milk protein ingredients for use in infant formulas: Research on biological functions. Trends Food Sci. Technol. 15:373-383.

de la Fuente, M. A., Y. Hemar, M. Tamehana, P. A. Munro, and H. Singh. 2002. Process-induced changes in whey proteins during the manufacture of whey protein concentrates. Int. Dairy J. $12: 361-369$

de Wit, J. N. 1998. Nutritional and functional characteristics of whey proteins in food products. J. Dairy Sci. 81:597-608.

Donovan, S. M. 2006. Role of human milk components in gastrointestinal development: Current knowledge and future needs. J. Pediatr. 149:S49-S61.

Elfstrand, L., H. Lindmark-Månsson, M. Paulsson, L. Nyberg, and B. Akesson. 2002. Immunoglobulins, growth factors and growth hormone in bovine colostrum and the effects of processing. Int. Dairy J. 12:879-887.

Ewaschuk, J. B., S. Unger, S. Harvey, D. L. O'Connor, and C. J. Field. 2011. Effect of pasteurization on immune components of milk: Implications for feeding preterm infants. Appl. Physiol. Nutr. Metab. $36: 175-182$.

Gezimati, J., H. Singh, and L. K. Creamer. 1996. Heat-induced interactions and gelation of mixtures of bovine $\beta$-lactoglobulin and serum albumin. J. Agric. Food Chem. 44:804-810.

Havea, P., H. Singh, and L. K. Creamer. 2002. Heat-induced aggregation of whey proteins: Comparison of cheese WPC with acid WPC and relevance of mineral composition. J. Agric. Food Chem. 50:4674-4681.

Hering, N. A., S. Andres, A. Fromm, E. A. van Tol, M. Amasheh, J. Mankertz, M. Fromm, and J. D. Schulzke. 2011. Transforming growth factor- $\beta$, a whey protein component, strengthens the intestinal barrier by upregulating claudin-4 in HT-29/B6 cells. J. Nutr. 141:783-789.

Jiang, R., V. Lopez, S. L. Kelleher, and B. Lönnerdal. 2011. Apoand holo-lactoferrin are both internalized by lactoferrin receptor via clathrin-mediated endocytosis but differentially affect ERKsignaling and cell proliferation in Caco-2 cells. J. Cell. Physiol. 226:3022-3031.

Kelley, L. 2012. Increasing the consumption of breast milk in lowbirth-weight infants: Can it have an impact on necrotizing enterocolitis? Adv. Neonatal Care 12:267-272.

Khalil, N. 1999. TGF-beta: From latent to active. Microbes Infect. $1: 1255-1263$.

Li, Y., M. V. Østergaard, P. Jiang, D. E. W. Chatterton, T. Thymann, A. S. Kvistgaard, and P. T. Sangild. 2013. Whey protein processing influences formula-induced gut maturation in preterm pigs. J. Nutr. 143:1934-1942.

Maheshwari, A., D. R. Kelly, T. Nicola, N. Ambalavanan, S. K. Jain, J. Murphy-Ullrich, M. Athar, M. Shimamura, V. Bhandari, C. Aprahamian, R. A. Dimmitt, R. Serra, and R. K. Ohls. 2011. 
TGF- 32 suppresses macrophage cytokine production and mucosal inflammatory responses in the developing intestine. Gastroenterology 140:242-253.

Manzoni, P., M. Rinaldi, S. Cattani, L. Pugni, M. G. Romeo, H. Messner, I. Stolfi, L. Decembrino, N. Laforgia, F. Vagnarelli, L. Memo, L. Bordignon, O. S. Saia, M. Maule, E. Gallo, M. Mostert, C. Magnani, M. Quercia, L. Bollani, R. Pedicino, L. Renzullo, P. Betta, F. Mosca, F. Ferrari, R. Magaldi, M. Stronati, and D. Farina. 2009. Bovine lactoferrin supplementation for prevention of late-onset sepsis in very low-birth-weight neonates: A randomized trial. JAMA 302:1421-1428.

McPherson, R. J., and C. L. Wagner. 2001. The effect of pasteurization on transforming growth factor alpha and transforming growth factor beta 2 concentrations in human milk. Adv. Exp. Med. Biol. 501:559-566.

Merewood, A., D. Brooks, H. Bauchner, L. MacAuley, and S. D. Mehta. 2006. Maternal birthplace and breastfeeding initiation among term and preterm infants: A statewide assessment for Massachusetts. Pediatrics 118:e1048-e1054.

Nabil, S., S. F. Gauthier, R. Drouin, P. E. Poubelle, and Y. Pouliot. 2011. In vitro digestion of proteins and growth factors in a bovine whey protein extract as determined using a computer-controlled dynamic gastrointestinal system (TIM-1). Food Dig. 2:13-22.

Nakamura, Y., M. Miyata, T. Ando, N. Shimokawa, Y. Ohnuma, R. Katoh, H. Ogawa, K. Okumura, and A. Nakao. 2009. The latent form of transforming growth factor- $\beta$ administered orally is activated by gastric acid in mice. J. Nutr. 139:1463-1468.
Nguyen, D. N., Y. Li, P. T. Sangild, S. B. Bering, and D. E. W. Chatterton. 2014b. Effects of bovine lactoferrin on the immature porcine intestine. Br. J. Nutr. 111:321-331.

Nguyen, D. N., P. T. Sangild, M. V. Ostergaard, S. B. Bering, and D. E. W. Chatterton. 2014a. Transforming growth factor- $\beta 2$ and endotoxin interact to regulate homeostasis via interleukin-8 levels in the immature intestine. Am. J. Physiol. Gastrointest. Liver Physiol. 307:G689-G699.

Planchon, S. M., C. A. Martins, R. L. Guerrant, and J. K. Roche. 1994. Regulation of intestinal epithelial barrier function by TGFbeta 1 . Evidence for its role in abrogating the effect of a $\mathrm{T}$ cell cytokine. J. Immunol. 153:5730-5739.

Roth-Walter, F., M. C. Berin, P. Arnaboldi, C. R. Escalante, S. Dahan, J. Rauch, E. Jensen-Jarolim, and L. Mayer. 2008. Pasteurization of milk proteins promotes allergic sensitization by enhancing uptake through Peyer's patches. Allergy 63:882-890.

Saito, S., M. Yoshida, M. Ichijo, S. Ishizaka, and T. Tsujii. 1993. Transforming growth factor-beta (TGF-beta) in human milk. Clin. Exp. Immunol. 94:220-224.

Togawa, J.-I., H. Nagase, K. Tanaka, M. Inamori, T. Umezawa, A. Nakajima, M. Naito, S. Sato, T. Saito, and H. Sekihara. 2002. Lactoferrin reduces colitis in rats via modulation of the immune system and correction of cytokine imbalance. Am. J. Physiol. Gastrointest. Liver Physiol. 283:G187-G195. 